\title{
Depressive Symptoms on the Geriatric Depression Scale and Suicide Deaths in Older Middle-aged Men: A Prospective Cohort Study
}

\section{Sang-Wook Yi, ${ }^{1,2}$}

${ }^{1}$ Department of Preventive Medicine and Public Health, Catholic Kwandong University College of Medicine, Gangneung; ${ }^{2}$ Institute for Clinical and Translational Research, Catholic Kwandong University, Gangneung, Korea

Objectives: Prospective evaluations of the associations between depressive symptoms and suicide deaths have been mainly performed in high-risk populations, such as individuals with psychiatric disorders or histories of self-harm. The purpose of this study was to prospectively examine whether more severe depressive symptoms assessed using the Geriatric Depression Scale (GDS) were associated with a greater risk of death from suicide in a general-risk population.

Methods: A total of 113478 men from the Korean Veterans Health Study (mean age, 58.9 years) who participated in a postal survey in 2004 were followed up for suicide mortality until 2010.

Results: Over 6.4 years of follow-up, 400 men died by suicide (56.7 deaths per 100000 person-years). More severe depressive symptoms were associated with greater risk of suicide death ( $p$ for trend $<0.001$ ). The unadjusted hazard ratios (HRs) in comparison to the absence of depression were 2.18 for mild depression, 2.13 for moderate depression, 3.33 for severe depression, and 3.67 for extreme depression. After adjusting for potential confounders, men with a potential depressive disorder had an approximate $90 \%$ higher mortality from suicide (adjusted HR, 1.92; 95\% confidence interval [Cl], 1.38 to $2.68 ; p<0.001$ ) than men without depression. Each fivepoint increase in the GDS score was associated with a higher risk of death by suicide (adjusted HR, 1.22; $p<0.001$ ). The value of the area under the receiver operating characteristics curve of GDS scores for suicide deaths was $0.61(95 \% \mathrm{Cl}, 0.58$ to 0.64$)$.

Conclusions: Depressive symptoms assessed using the GDS were found to be a strong independent predictor of future suicide. However, the estimate of relative risk was weaker than would be expected based on retrospective psychological autopsy studies.

Key words: Asia, Cohort studies, Depression, Men, Suicide

\section{INTRODUCTION}

Korea had the highest rate of suicide deaths among the Or-

Received: January 26, 2016 Accepted: April 1, 2016

Corresponding author: Sang-Wook Yi, MD, PhD

24 Beomil-ro 579beon-gil, Gangneung 25601, Korea

Tel: +82-33-649-7468, Fax: +82-33-641-1074

E-mail: flyhigh@cku.ac.kr

This is an Open Access article distributed under the terms of the Creative Commons Attribution Non-Commercial License (http://creativecommons.org/licenses/bync/3.0/) which permits unrestricted non-commercial use, distribution, and reproduction in any medium, provided the original work is properly cited. ganization for Economic Cooperation and Development countries from 2003 to 2012 (26 to 34 per 100000 ) [1], with over 10 000 people per year dying by suicide. In many countries, measures to prevent suicide are a high priority. Many retrospective studies, such as psychological autopsy studies, have reported a strong relationship between depression and suicide (e.g., a meta-analysis found the odds ratio of a mood disorder for suicide to be 13.4 , with a $95 \%$ confidence interval [CI] of 8.1 to 
22.4) [2], however, it is impossible to rule out biases related to retrospective studies, such as an overestimation of the association and recall bias [3]. Prospective investigations of the relationship between depression and suicide deaths have been mainly performed in psychiatric patients, who may not reflect persons with depressive disorders in the general population [4]. Few studies have prospectively evaluated the association of depressive symptoms with suicide deaths in general or lowrisk populations [5-9].

The Geriatric Depression Scale (GDS) is a 30-item self-reported assessment tool used to screen for depression in the elderly population, and it is widely administered in clinical and research settings [10]. Although depressive symptoms as assessed using the GDS have been associated with suicidal ideation in several cross-sectional studies [11,12], few studies have prospectively examined the associations of depressive symptoms as assessed by the full 30-item GDS with death by suicide [6].

The purpose of this study was to prospectively examine whether the severity of depressive symptoms as assessed using the Korean translation of the GDS increased deaths by suicide in older middle-aged Korean men, specifically in Korean veterans of the Vietnam War. Since all able-bodied men are required to serve in the military in Korea, this study cohort was not necessarily an occupational cohort, but was rather a Vietnam-experience cohort. The study participants had a lower mortality due to suicide (crude mortality, 56.7 deaths per 100000 personyears from 2004 to 2010; sex-, age-, and calendar-year-standardized mortality ratio, $0.82 ; 95 \% \mathrm{Cl}, 0.74$ to 0.91 ) than would have been expected from the general Korean population.

\section{METHODS}

\section{Study Participants and Follow-up}

We identified 164208 living men in June 2004 among the 187897 men in the Korean Veterans Health Study, after excluding 23689 men who had died or emigrated. On July 27, 2004, a postal survey was sent to 164208 men, to which 117609 men $(71.6 \%)$ replied. Men $(n=4131)$ with missing body mass index (BMI) information or with uncertain residential status after the initial survey were excluded. The final study population included 113478 men. This study was approved by the institutional review board of Kwandong University.

Deaths by suicide were assessed using the 2004-2010 death records of the National Statistical Office. Ascertainment of death was performed through record linkage at the national level and was considered complete. Suicide was identified by the International Classification of Diseases, 10th revision codes X60-X84.

\section{Measures of Depressive Symptoms and Co-variables}

The self-administered GDS, with 30 items in a yes/no format and a total score of zero to 30, was used to assess depressive symptoms [10]. The Korean-language translation of the GDS was developed by two medical doctors and several graduate students in public health. Internal consistency was assessed using Cronbach's alpha and was found to be 0.929 in a complete data analysis.

The participants were categorized into five groups based on quartiles and the highest decile of the GDS score: no depressive symptoms (0-16), mild depressive symptoms (17-23), moderate depressive symptoms (24-27), severe depressive symptoms (28-29), and extreme depressive symptoms. They were also classified into two groups reflecting severe and nonsevere depression (no to moderate depression, 0-27; severe depression, 28-30) and into two groups based on the presence or absence of depression (no depression, 0-16; depression, 17$30)$, using a cut-off score drawn from previous research $[13,14]$.

Self-reported information on self-rated health, smoking history, alcohol drinking frequency, physical activity, BMI, the number of close friends, and household monthly income were collected through the survey. BMI was calculated as self-reported weight divided by self-reported height squared $\left(\mathrm{kg} / \mathrm{m}^{2}\right)$. Participants with pre-existing cancer at baseline were identified through the National Cancer Incidence Database [15].

\section{Statistical Analysis}

Among the 113478 participants, 19114 (16.8\%) had one or more missing items on the GDS. Substitution of the missing data with the most common answer for each item (mode substitution) was performed for the GDS items. A GDS data analysis that excluded participants with at least one missing GDS item was also performed.

In order to compare the baseline characteristics according to depressive symptoms, the chi-square test and analysis of variance were applied. Hazard ratios (HRs) were calculated using the Cox proportional hazards model. The variables adjusted for in the Cox model included age at baseline (years), 
smoking history (current, past, or never smoker, or missing information), alcohol drinking frequency ( $\geq 5 \mathrm{~d} / \mathrm{wk}, 1-4 \mathrm{~d} / \mathrm{wk}$, $<1 \mathrm{~d} /$ wk, past drinker, never drinker, or missing information), BMI $\left(\mathrm{kg} / \mathrm{m}^{2} ;<18.5,18.5-24.9,25-29.9\right.$, or $\left.\geq 30\right)$, self-rated health (good, fair, or poor), the presence of pre-existing cancer at baseline (yes or no), and physical activity ( $\geq 10$ minutes of moderate or vigorous activity at least once per month vs. no activity), the number of close friends ( $\leq 1,2-5$, or $\geq 6)$, and household monthly income (1170 Korean won [KRW] $=1$ USD as of August 1, 2004; <500 000 KRW, 500 000-990 000 KRW, 1 000 000-1 $490000 \mathrm{KRW}, \geq 1500000 \mathrm{KRW}$, or missing information).

Table 1. Characteristics of the Korean middle-aged male participants according to the severity of depressive symptoms

\begin{tabular}{|c|c|c|c|c|c|}
\hline \multicolumn{2}{|l|}{ Characteristics } & \multirow{2}{*}{$\begin{array}{c}\begin{array}{c}\text { Total } \\
\text { (n=113 478) }\end{array} \\
58.9 \pm 3.5\end{array}$} & \multirow{2}{*}{$\begin{array}{c}\text { None to moderate } \\
\text { symptoms } \\
\text { (n=86 270) } \\
58.9 \pm 3.6\end{array}$} & \multirow{2}{*}{$\begin{array}{c}\begin{array}{c}\text { Severe symptoms } \\
\text { (n=27 208) }\end{array} \\
\\
58.7 \pm 3.2\end{array}$} & \multirow{2}{*}{$\begin{array}{c}\boldsymbol{p}^{\text {-value }}{ }^{1} \\
<0.001^{2}\end{array}$} \\
\hline Age (mean \pm SD) & & & & & \\
\hline \multirow[t]{4}{*}{ Smoking history } & Current smoker & 40756 (35.9) & 30635 (35.5) & 10121 (37.2) & $<0.001$ \\
\hline & Past smoker & 51949 (45.8) & $39715(46.0)$ & $12234(45.0)$ & \\
\hline & Never smoker & 19626 (17.3) & $15118(17.5)$ & $4508(16.6)$ & \\
\hline & Missing & $1147(1.0)$ & $802(0.9)$ & $345(1.3)$ & \\
\hline \multirow{6}{*}{$\begin{array}{l}\text { Alcohol drinking frequency } \\
\text { (d/wk) }\end{array}$} & $\geq 5$ & 12251 (10.8) & $9606(11.1)$ & $2645(9.7)$ & $<0.001$ \\
\hline & $1-4$ & 43076 (38.0) & 33794 (39.2) & $9282(34.1)$ & \\
\hline & $<1$ & 41011 (36.1) & 30649 (35.5) & $10362(38.1)$ & \\
\hline & Past drinker & $7411(6.5)$ & $5311(6.2)$ & $2100(7.7)$ & \\
\hline & Never drinker & $8265(7.3)$ & $5878(6.8)$ & $2387(8.8)$ & \\
\hline & Missing & $1464(1.3)$ & $1032(1.2)$ & $432(1.6)$ & \\
\hline Physical activity & Yes & 37792 (33.3) & $26176(30.3)$ & $11616(42.7)$ & $<0.001$ \\
\hline \multirow[t]{4}{*}{ Body mass index $\left(\mathrm{kg} / \mathrm{m}^{2}\right)$} & $<18.5$ & $2918(2.6)$ & $1875(2.2)$ & $1043(3.8)$ & $<0.001$ \\
\hline & $18.5-24.9$ & 77556 (68.3) & 58704 (68.0) & 18852 (69.3) & \\
\hline & $25.0-29.9$ & 31613 (27.9) & 24637 (28.6) & $6976(25.6)$ & \\
\hline & $\geq 30$ & $1391(1.2)$ & $1054(1.2)$ & $337(1.2)$ & \\
\hline \multirow[t]{3}{*}{ No. of close friends } & $\leq 1$ & $35918(31.7)$ & $25052(29.0)$ & $10866(39.9)$ & $<0.001$ \\
\hline & $2-5$ & $45884(40.4)$ & 35207 (40.8) & 10677 (39.2) & \\
\hline & $\geq 6$ & 31676 (27.9) & 26011 (30.2) & 5665 (20.8) & \\
\hline \multirow{5}{*}{$\begin{array}{l}\text { Household income } \\
(\text { Korean won } / \mathrm{mo})^{3}\end{array}$} & $<500000$ & $10496(9.2)$ & $6312(7.3)$ & $4184(15.4)$ & $<0.001$ \\
\hline & $500000-990000$ & $23201(20.4)$ & $15820(18.3)$ & $7381(27.1)$ & \\
\hline & $1000000-1490000$ & 27098 (23.9) & $20375(23.6)$ & $6723(24.7)$ & \\
\hline & $\geq 1500000$ & 47885 (42.2) & 40999 (47.5) & $6886(25.3)$ & \\
\hline & Missing & $4798(4.2)$ & $2764(3.2)$ & $2034(7.5)$ & \\
\hline \multirow[t]{3}{*}{ Self-rated health } & Good & $10590(9.3)$ & $10109(11.7)$ & 481 (1.8) & $<0.001$ \\
\hline & Fair & 36541 (32.2) & 32067 (37.2) & $4474(16.4)$ & \\
\hline & Poor & 66347 (58.5) & 44094 (51.1) & 22253 (81.8) & \\
\hline Pre-existing cancer & Yes & $3465(3.1)$ & $2550(3.0)$ & $915(3.4)$ & 0.001 \\
\hline \multirow{5}{*}{$\begin{array}{l}\text { Depressive symptoms }{ }^{4} \\
\text { (GDS score) }\end{array}$} & None $(0-16)$ & $28496(25.1)$ & $28496(33.0)$ & $0(0.0)$ & $<0.001$ \\
\hline & Mild (17-23) & $29725(26.2)$ & $29725(34.5)$ & $0(0.0)$ & \\
\hline & Moderate (24-27) & $28049(24.7)$ & 28049 (32.5) & $0(0.0)$ & \\
\hline & Severe (28-29) & 20837 (18.4) & $0(0.0)$ & 20837 (76.6) & \\
\hline & Extreme (30) & $6371(5.6)$ & $0(0.0)$ & $6371(23.4)$ & \\
\hline
\end{tabular}

Values are presented as number (\%).

GDS, Geriatric Depression Scale; SD, standard deviation.

${ }^{1}$ Calculated by chi-square analysis.

${ }^{2}$ Calculated by analysis of variance.

${ }^{3} 1170$ Korean won was approximately one US dollar as of August 1, 2004.

${ }^{4}$ Cut-off scores based on quartiles and the highest decile. 
Area under the receiver operating characteristics curve (AUC) was calculated using Proc Logistic (ROC statement) in SAS. For a diagnostic test, AUC values of 1.0 and 0.5 represent a perfect test or an uninformative test, respectively.

SAS version 9.4 (SAS Institute Inc., Cary, NC, USA) was used for statistical analysis. The two-sided $p$-value was calculated, and $p$-values $<0.05$ were considered to indicate statistical significance.

\section{RESULTS}

\section{Characteristics of the Participants}

Over the course of 705175 person-years of follow-up, 400 men died by suicide (56.7 per 100000 person-years). The mean (standard deviation) age and GDS score of the participants at baseline were 58.9 (3.5) years and 21.1 (7.6), respectively. Men with severe depressive symptoms were somewhat younger than those with no to moderate symptoms, and they contained more current smokers and fewer frequent drinkers, were thinner and less healthy, and had fewer close friends, low earnings, and more pre-existing cancer (Table 1).

\section{Suicide and Depressive Symptoms Assessed Using the Geriatric Depression Scale}

The unadjusted estimate of relative risk associated with se- vere depressive symptoms was 1.93 compared with no to moderate symptoms. Each five-point increase in the GDS score was associated with a $34 \%$ higher risk of suicide death in the unadjusted analysis. Increasing depressive symptoms across the five categories was associated with an increasing HR of suicide ( $p$ for trend $<0.001$ ) (Table 2). Participants with depressive symptoms had a $156 \%$ higher risk of death by suicide $(H R=2.56)$ than men with no depression. Adjusting for potential risk factors of suicide attenuated the association between depressive symptoms as assessed by the GDS and suicide, although it remained present. When the analysis was restricted to men with complete information for each GDS item, the associations of depressive symptoms with the risk of death by suicide were unchanged (Table 3 ). The AUC values were $0.61(95 \% \mathrm{Cl}, 0.58$ to 0.64 ; all participants) and $0.60(95 \% \mathrm{Cl}$, 0.57 to 0.63 ; men with no missing information for any GDS item), for the unbinned total score of the GDS.

\section{DISCUSSION}

The presence of more severe depressive symptoms as assessed by the GDS was associated with a greater risk of death by suicide after adjusting for potential confounders, such as substance use (alcohol consumption frequency and smoking history), social support (number of close friends), socioeco-

Table 2. HRs of suicide according to depressive symptoms in Korean middle-aged men ( $\mathrm{n}=113478)^{1}$

\begin{tabular}{|c|c|c|c|c|c|c|c|}
\hline \multirow{2}{*}{\multicolumn{2}{|c|}{ Categories of depressive symptoms (score) }} & \multirow{3}{*}{$\begin{array}{c}\begin{array}{c}\text { Person- } \\
\text { years }\end{array} \\
705175\end{array}$} & \multirow{3}{*}{$\begin{array}{c}\begin{array}{c}\text { No. of } \\
\text { suicides }\end{array} \\
400\end{array}$} & \multicolumn{2}{|c|}{ Unadjusted analysis } & \multicolumn{2}{|c|}{ Adjusted analysis ${ }^{2}$} \\
\hline & & & & \multirow{2}{*}{$\begin{array}{c}\mathbf{H R}(\mathbf{9 5} \% \mathbf{~ C I )} \\
1.34(1.24,1.45)\end{array}$} & \multirow{2}{*}{$\begin{array}{c}\boldsymbol{p} \text {-value } \\
<0.001\end{array}$} & \multirow{2}{*}{\begin{tabular}{r|}
$\mathbf{H R}(\mathbf{9 5} \% \mathbf{~ C I})$ \\
$1.22(1.11,1.34)$
\end{tabular}} & \multirow{2}{*}{$\begin{array}{l}p \text {-value } \\
<0.001\end{array}$} \\
\hline Total GDS score (0-30) & Five-point score increase & & & & & & \\
\hline & Severe (28-30) & 167569 & 150 & $1.93(1.57,2.36)$ & $<0.001$ & $1.47(1.18,1.82)$ & $<0.001$ \\
\hline \multirow[t]{4}{*}{ Five-group analysis $(1)^{3}$} & None $(0-16)$ & 178995 & 47 & 1.00 (reference) & & 1.00 (reference) & \\
\hline & Severe (28-29) & 128143 & 112 & $3.33(2.37,4.68)$ & $<0.001$ & $2.27(1.55,3.31)$ & $<0.001$ \\
\hline & Extreme (30) & 39426 & 38 & $3.67(2.39,5.63)$ & $<0.001$ & $2.64(1.66,4.19)$ & $<0.001$ \\
\hline & Trend test ${ }^{4}$ & 705175 & 400 & $1.35(1.24,1.46)$ & $<0.001$ & $1.21(1.11,1.33)$ & $<0.001$ \\
\hline Two-group analysis $(2)^{5}$ & No depression (0-16) & 178995 & 47 & 1.00 (reference) & & 1.00 (reference) & \\
\hline
\end{tabular}

$\mathrm{HR}$, hazard ratio; $\mathrm{Cl}$, confidence interval; GDS, Geriatric Depression Scale.

'In 19114 men with at least one missing GDS item, each missing GDS item was substituted with the most common answer for the item reported by all participants; HRs were calculated using the Cox proportional hazards model.

${ }^{2}$ Adjusted for age at baseline, smoking history, alcohol drinking frequency, physical activity, body mass index, self-rated health, number of close friends, preexisting cancer, and household monthly income.

${ }^{3}$ Cut-off score based on quartiles and the highest decile.

${ }^{4}$ The five categories of depressive symptoms were analyzed as ordinal variables (1, 2, 3, 4, and 5).

${ }^{5}$ Cut-off score based on previous research on Koreans. 
Table 3. HRs of suicides by depressive symptoms in Korean middle-aged men with no missing GDS items ( $\mathrm{n}=94$ 364)

\begin{tabular}{|c|c|c|c|c|c|c|c|}
\hline \multirow{2}{*}{\multicolumn{2}{|c|}{ Categories of depressive symptoms (score) }} & \multirow{3}{*}{$\begin{array}{c}\begin{array}{c}\text { Person- } \\
\text { years }\end{array} \\
587665\end{array}$} & \multirow{3}{*}{$\begin{array}{c}\begin{array}{c}\text { No. of } \\
\text { suicides }\end{array} \\
311\end{array}$} & \multicolumn{2}{|c|}{ Unadjusted analysis } & \multicolumn{2}{|c|}{ Adjusted analysis ${ }^{2}$} \\
\hline & & & & \multirow{2}{*}{$\begin{array}{r}\text { HR (95\% CI) } \\
1.31(1.2,1.43)\end{array}$} & \multirow{2}{*}{$\begin{array}{l}\boldsymbol{p} \text {-value } \\
<0.001\end{array}$} & \multirow{2}{*}{$\begin{array}{c}\text { HR }(\mathbf{9 5} \% \mathbf{~ C I}) \\
1.19(1.07,1.31)\end{array}$} & \multirow{2}{*}{$\begin{array}{c}\boldsymbol{p} \text {-value } \\
0.001\end{array}$} \\
\hline Total GDS score (0-30) & Five score increase & & & & & & \\
\hline \multirow[t]{2}{*}{ Two-group analysis $(1)^{3}$} & No-to-moderate $(0-27)$ & 458128 & 201 & 1.00 (reference) & & 1.00 (reference) & \\
\hline & Severe (28-30) & 129537 & 110 & $1.94(1.53,2.44)$ & $<0.001$ & $1.51(1.18,1.93)$ & 0.001 \\
\hline \multirow[t]{6}{*}{ Five-group analysis $(1)^{3}$} & No $(0-16)$ & 159152 & 41 & 1.00 (reference) & & 1.00 (reference) & \\
\hline & Mild (17-23) & 155791 & 88 & $2.19(1.51,3.18)$ & $<0.001$ & $1.82(1.23,2.69)$ & 0.003 \\
\hline & Moderate (24-27) & 143185 & 72 & $1.95(1.33,2.87)$ & 0.001 & $1.45(0.96,2.20)$ & 0.08 \\
\hline & Severe (28-29) & 93113 & 78 & $3.25(2.23,4.75)$ & $<0.001$ & $2.25(1.48,3.42)$ & $<0.001$ \\
\hline & Extreme (30) & 36424 & 32 & $3.41(2.15,5.42)$ & $<0.001$ & $2.29(1.38,3.78)$ & 0.001 \\
\hline & Trend test ${ }^{4}$ & 587665 & 311 & $1.32(1.21,1.45)$ & $<0.001$ & $1.19(1.07,1.32)$ & 0.001 \\
\hline \multirow[t]{2}{*}{ Two-group analysis $(2)^{5}$} & No depression (0-16) & 159152 & 41 & 1.00 (reference) & & 1.00 (reference) & \\
\hline & Depression (17-30) & 428513 & 270 & $2.45(1.76,3.40)$ & $<0.001$ & $1.80(1.26,2.58)$ & 0.001 \\
\hline
\end{tabular}

HR, hazard ratio; Cl, confidence interval; GDS, Geriatric Depression Scale.

'In 19114 men with at least one missing GDS item were excluded; HRs were calculated using the Cox proportional hazards model.

${ }^{2}$ Adjusted for age at baseline, smoking history, alcohol drinking frequency, physical activity, body mass index, self-rated health, number of close friends, preexisting cancer, and household monthly income.

${ }^{3}$ Cut-off score based on quartiles and the highest decile.

${ }^{4}$ The five categories of depressive symptoms were analyzed as ordinal variables $(1,2,3,4$, and 5).

${ }^{5}$ Cut-off score based on previous research on Koreans.

nomic status (monthly household income), physical health status (BMI, self-rated health, and the presence of pre-existing cancer), and physical activity. Men with depressive symptoms had an approximately $90 \%$ higher risk of suicide death than men without depression after adjusting for potential risk factors. The magnitude of this association, however, was weaker than has been reported in previous psychological autopsy studies [2].

This study confirmed the strong relationship between depressive symptoms and suicide death, in accordance with previous prospective studies of general or low-risk populations [59]. Reducing depressive symptoms in the general population and properly managing people with depressive symptoms should be top priorities for reducing the burden of suicide.

The current estimate of the relative risk of depressive symptoms for suicide deaths was lower than the relative risk reported by previous prospective studies of the general populations of other countries [5-7,9], as well as of Korean Vietnam War veterans [8]. The prevalence of depressive symptoms was higher in our study participants than in other populations. The mean GDS score in the current study was lower than has been reported for persons with mood disorders, but was substantially higher than has been reported for non-depressive groups in previous Korean studies $[13,14]$. The majority $(75 \%)$ of participants in the current study could be considered indi- viduals who potentially had a depressive disorder based on previous studies $[13,14]$. In a population with a high prevalence of potential depressive disorder, the discriminatory power of depression assessed by the GDS for suicide risk might be lower than that of other measures of depression, such as the Beck Depression Inventory (BDI). Previous research on Korean Vietnam War veterans showed that severe depressive symptoms assessed by the BDI were associated with a $240 \%$ higher mortality from suicide ( $\mathrm{HR}, 3.4 ; 95 \% \mathrm{Cl}, 1.5$ to 7.7$)$ in comparison with no to moderate depressive symptoms [8].

The AUC value of the GDS score for suicide deaths found in the present study (HR, $0.61 ; 95 \% \mathrm{Cl}, 0.58$ to 0.64 ) indicated that the GDS can discriminate between individuals who tend to die by suicide or not, although its predictive performance was weak. Our observed discriminatory power of GDS for suicide death was lower than has been reported for suicidal ideation in previous research $[11,12]$. However, this was expected because suicidal ideation or even suicide attempts are not perfect predictors of suicide [16]. For suicide deaths, the AUC value of GDS among men in the current study was similar to that of some measures of potential suicidality [17], but seemed to be lower than others $[8,18]$. Given both the lower AUC and the relatively low HRs associated with the GDS in the current study, the GDS may be less predictive of suicide death than other measures of depression or suicidality, although this con- 
clusion may be limited to populations with a potentially higher prevalence of depression, such as Vietnam War veterans.

\section{Strength and Limitations of the Study}

The prospective follow-up of suicide deaths is a clear strength of this study. The number of suicide deaths $(n=400)$ is one of the largest reported in research on suicide. The complete follow-up enhanced the integrity of this study. This study also adjusted for many potential risk factors for suicide, including alcohol consumption, smoking history, exercise, physical health status, social support, and socioeconomic status.

This study also has some limitations. First, depressive symptoms were measured once, although the intensity of depressive symptoms may change over time. The estimated association based on one baseline assessment may underestimate the true effect [8]. Second, suicide deaths were not verified independently of death certificates. However, potential misclassification most likely would be non-differential according to depressive symptoms. Third, our study population had a lower suicide mortality than the general male population in Korea. We do not think, however, that the lower suicide mortality substantially impacted the association between depressive symptoms and suicide mortality [19]. Fourth, the homogenous study population (all Koreans) may be deemed a limitation regarding the generalizability of the present study, as the strength of the associations of depressive symptoms with suicide may differ by ethnicity, culture, age, and gender $[6,8,20]$. However, the presence of a positive association between depressive symptoms and suicide deaths is likely universal.

In conclusion, this large prospective study confirmed depressive symptoms to be a strong independent predictor of future suicide. However, the estimate of relative risk was weaker than expected based on retrospective studies, such as psychological autopsy studies.

\section{ACKNOWLEDGEMENTS}

The authors sincerely thank the staff of the National Statistical Office of Korea for providing the national mortality data. This paper was supported by a research grant of the Ministry of Patriots and Veterans Affairs (MPVA) of Korea. This work was also supported by a research fund of Catholic Kwandong University.

\section{CONFLICT OF INTEREST}

The author has no conflicts of interest associated with the material presented in this paper.

\section{ORCID}

Sang-Wook Yi http://orcid.org/0000-0002-6656-6205

\section{REFERENCES}

1. OECD. OECD health statistics 2015; frequently requested data [cited 2016 Jan 23]. Available from: http://www.oecd.org/ health/health-systems/OECD-Health-Statistics-2015-Frequently-Requested-Data.xls.

2. Yoshimasu K, Kiyohara C, Miyashita K; Stress Research Group of the Japanese Society for Hygiene. Suicidal risk factors and completed suicide: meta-analyses based on psychological autopsy studies. Environ Health Prev Med 2008;13(5):243-256.

3. Hjelmeland H, Dieserud G, Dyregrov K, Knizek BL, Leenaars AA. Psychological autopsy studies as diagnostic tools: are they methodologically flawed? Death Stud 2012;36(7):605626.

4. Agerbo E. High income, employment, postgraduate education, and marriage: a suicidal cocktail among psychiatric patients. Arch Gen Psychiatry 2007;64(12):1377-1384.

5. Bramness JG, Walby FA, Hjellvik V, Selmer R, Tverdal A. Self-reported mental health and its gender differences as a predictor of suicide in the middle-aged. Am J Epidemiol 2010;172 (2):160-166.

6. Sun WJ, Xu L, Chan WM, Lam TH, Schooling CM. Depressive symptoms and suicide in 56,000 older Chinese: a Hong Kong cohort study. Soc Psychiatry Psychiatr Epidemiol 2012;47(4): 505-514.

7. Tamakoshi A, Ohno Y, Yamada T, Aoki K, Hamajima N, Wada M, et al. Depressive mood and suicide among middle-aged workers: findings from a prospective cohort study in Nagoya, Japan. J Epidemiol 2000;10(3):173-178.

8. Yi SW, Hong JS. Depressive symptoms and other risk factors predicting suicide in middle-aged men: a prospective cohort study among Korean Vietnam War veterans. PeerJ 2015;3: e1071.

9. Schneider B, Lukaschek K, Baumert J, Meisinger C, Erazo N, Ladwig KH. Living alone, obesity, and smoking increase risk for suicide independently of depressive mood findings from 
the population-based MONICA/KORA Augsburg cohort study. J Affect Disord 2014;152-154:416-421.

10. Yesavage JA, Brink TL, Rose TL, Lum O, Huang V, Adey M, et al. Development and validation of a geriatric depression screening scale: a preliminary report. J Psychiatr Res 1982-1983;17 (1):37-49.

11. Cheng ST, Yu EC, Lee SY, Wong JY, Lau KH, Chan LK, et al. The geriatric depression scale as a screening tool for depression and suicide ideation: a replication and extention. Am J Geriatr Psychiatry 2010;18(3):256-265.

12. Heisel MJ, Flett GL, Duberstein PR, Lyness JM. Does the geriatric depression scale (GDS) distinguish between older adults with high versus low levels of suicidal ideation? Am J Geriatr Psychiatry 2005;13(10):876-883.

13. Kim JY, Park JH, Lee JJ, Huh Y, Lee SB, Han SK, et al. Standardization of the Korean version of the geriatric depression scale: reliability, validity, and factor structure. Psychiatry Investig 2008;5(4):232-238.

14. Cho MJ, Bae JN, Suh GH, Hahm BJ, Kim JK, Lee DW, et al. Validation of geriatric depression scale, Korean version (GDS) in the assessment of DSM-III-R major depression. J Korean Neu- ropsychiatr Assoc 1999;38(1):48-63 (Korean).

15. Yi SW, Hong JS, Ohrr H, Yi JJ. Agent Orange exposure and disease prevalence in Korean Vietnam veterans: the Korean veterans health study. Environ Res 2014;133:56-65.

16. Parra Uribe I, Blasco-Fontecilla H, García-Parés G, Giró Batalla M, Llorens Capdevila M, Cebrià Meca A, et al. Attempted and completed suicide: not what we expected? J Affect Disord 2013;150(3):840-846.

17. Harriss L, Hawton K. Suicidal intent in deliberate self-harm and the risk of suicide: the predictive power of the Suicide Intent Scale. J Affect Disord 2005;86(2-3):225-233.

18. McMillan D, Gilbody S, Beresford E, Neilly L. Can we predict suicide and non-fatal self-harm with the Beck Hopelessness Scale? A meta-analysis. Psychol Med 2007;37(6):769-778.

19. Jee SH, Kivimaki M, Kang HC, Park IS, Samet JM, Batty GD. Cardiovascular disease risk factors in relation to suicide mortality in Asia: prospective cohort study of over one million Korean men and women. Eur Heart J 2011;32(22):2773-2780.

20. Bjerkeset O, Romundstad P, Gunnell D. Gender differences in the association of mixed anxiety and depression with suicide. Br J Psychiatry 2008;192(6):474-475. 